\title{
Study on operating load of the compression ignition engine
}

Operation of car engines definitely shows varied values of parameters such as crankshaft speed or load. This paper presents the research and results on load and crankshaft speed in a compression ignition engine. Therefore, the research focused on an operation of a passenger car under urban and non-urban conditions. Our NI Diadem Analysis-based research referred to the data acquired by an OBD-II system. The results obtained enabled some layered charts to depict a frequency of operating states as specified by engine load and speed as well as histograms of these parameters in individual rides. Our investigation showed that operating conditions have an impact on engine operating states. In urban conditions, our engine operated within the range of 700-2000 rpm but idle was more than $50 \%$ of the time and load in most cases was not higher than 20\%. In non-urban conditions, our engine operated within the range from 700 to 3000 rpm and load was up to $70 \%$.

Key words: compression ignition engine, load, operating condition

\section{Introduction}

The share of car traffic in urban areas in developed and developing countries is increasing. This tendency has been confirmed by the release on road traffic in 2016 by the Great Britain's Department for Transport. This document shows that vehicle motor traffic (VMT) in urban areas was by about $5 \%$ higher than in 2007 and reached 31.4 billion vehicle miles, whereas vehicle motor traffic in non-urban areas increased by the same percentage to reach 58.5 billion vehicle miles [1].

Engine load and speed have an impact on service life of various engine components and fuel consumption [2, 3]. Moreover, toxic emissions of, e.g. particulates or nitrogen oxides are largely impacted if these operational parameters vary. A typical method to achieve combustion with low content of soot and nitrogen oxides and highly efficient operation is the use of the diesel particulate filter (DPF) and the exhaust gas recirculation (EGR) valve capable of increasing air fuel ratio. Another method is the RCCI burning which is a variation of the HCCI method and is capable of reducing toxic emissions and maintaining high thermal efficiency for medium and large loads [4]. It is, therefore, important to examine the most frequent operating states of a car engine in urban and non-urban conditions.

Toxic emissions emitted by various drive units can be compared by means of a CADC test driving cycle which relies on the statistical analysis of European real driving patterns, developed in an European project - ARTEMIS. Such a driving cycle covers three traffic situations: urban, non-urban and motorway. The authors $[5,6]$ claim that this approach is more reliable than the NEDC test procedure which is a laboratory-based defined speed change and a measurement of fuel consumption and toxic emissions.

While driving a car, there are varied loads so engine operation should be properly controlled. Such a control relies on transition from one to another operating point defined by speed, load and fuel consumption to achieve the best possible dynamic transition between operating states and the lowest possible specific fuel consumption [7].
The car engine operates under steady-state conditions but only in few traffic situations, e.g. in non-urban areas. The most frequent traffic operating conditions are transient conditions, e.g. the vehicle often speeds up and slows down in urban areas [8]. Certain experiments on how transient conditions impact the operation of a turbocharged diesel engine are discussed in [9].

Engine load is also impacted by ambient conditions, especially crosswind and headwind so a correct engine operation control should be accompanied by vehicle aerodynamics. The work [10] discusses the correlation between the coefficient of drag and speed and direction of wind for the truck.

Measured by means the PEMS system, emissions of nitrogen oxides and carbon dioxide have turned out to be higher for more varied topographically routes and more dynamic driving styles [11]. The PEMS system is a variation of the RDE test that relies on measuring emissions of toxic substances during real driving, regarding factors such as: speed, topography, ambient temperature, load. The $\mathrm{NO}_{\mathrm{x}}$ emission is also reduced in non-urban areas [12]. The study [13] shows that energy consumption calculated from the TTV analysis for an up-and-down route is larger for compression-ignition engine than the electric engine.

This paper discusses the research results on engine operating states, i.e. load and crankshaft speed in urban and non-urban areas. The measurements were performed with a recording device that cooperates with an EOBD protocol compatible diagnostic connector.

\section{Research object}

The research object was a four-cylinder diesel engine 2.0 MZR-CD with a power of $100 \mathrm{~kW}$ (Fig. 1). The engine was mounted in the passenger car Mazda 6 wagon. The engine is directly fuel injected with a Common Rail system. The Euro 3 emission standards are satisfied by the solution of the engine cooperating with the diesel particulate filter (DPF). The engine is fitted with a variable-geometry turbocharger. The basic engine technical parameters are in Table 1. 


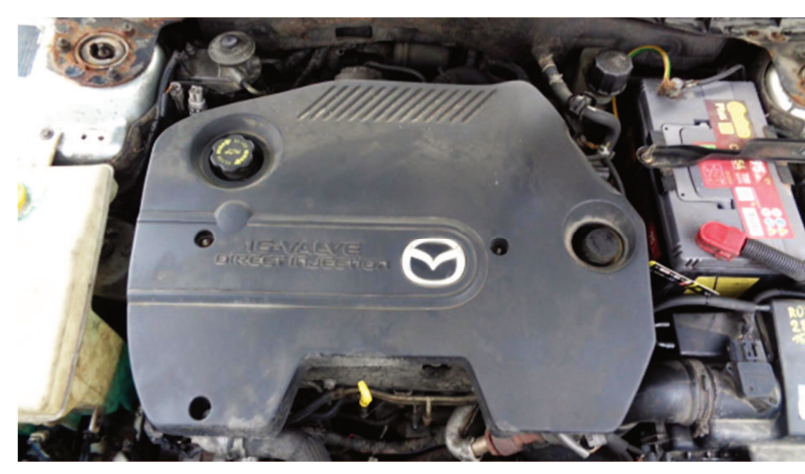

Fig. 1. Research engine 2.0 MZR-CD

Table 1. 2.0 MZR-CD basic technical parameters

\begin{tabular}{|l|c|}
\hline Year of production & 2004 \\
\hline Cylinder capacity & $1998 \mathrm{~cm}^{3}$ \\
\hline Ignition type & CI \\
\hline Injection type & Common Rail \\
\hline Charge type & Variable-geometry turbocharger \\
\hline Power & $100 \mathrm{~kW} / 136 \mathrm{hp}(3500 \mathrm{rpm})$ \\
\hline Torque & $310 \mathrm{Nm}(2000 \mathrm{rpm})$ \\
\hline Engine mounting & transverse \\
\hline Number of cylinders & 4 \\
\hline Arrangement of cylinders & in-line \\
\hline Camshaft location & SOHC $(\mathrm{OHC})$ \\
\hline Number of valves & 16 \\
\hline Compression ratio & $18: 1$ \\
\hline Bore & $86 \mathrm{~mm}$ \\
\hline Piston stroke & $86 \mathrm{~mm}$ \\
\hline Emission standard & Euro 3 \\
\hline
\end{tabular}

\section{Test bench}

Load in the compression-ignition engine passenger car in urban and non-urban traffic is measured with the TEXA OBD Log (Fig. 2). Engine load value is directly available in OBD II information and it is expressed by percent. The recording device is capable of real-time registering engine parameters such as vehicle speed, crankshaft speed, coolant temperature, engine load, air mass flow, air temperature, intake air pressure, fuel pressure and battery voltage. There are also registered route-specific data like a vehicle identification number, route numbers, starting and ending hours. The recording device supports the following EOBD protocols which are in line with the J1850-41.6, J1850-10.4, ISO 9141-2 K/L, CAN (Control Area Network ISO 11898).

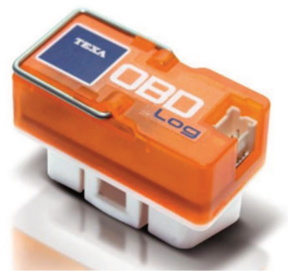

Fig. 2. TEXA OBD Log [14]

The device has been connected to the vehicle with an EOBD diagnostic connector. Entering the selected parameters was followed by transferring the data into the computer by a special software of OBD Log SW Suite. Data analysis were performed in NI Diadem software. A general diagram of data collection and investigation is depicted in Figure 3.

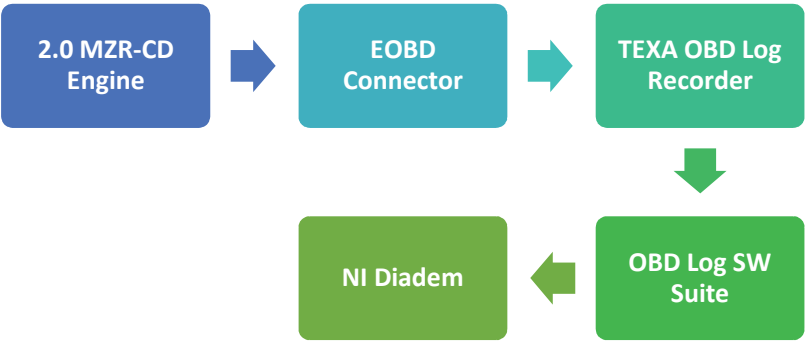

Fig. 3. Diagram of data collection and investigation

\section{Research methodology}

The vehicle with the connected DVR TEXA OBD Log operated on urban and non-urban routes of different lengths and varied loads. The recording device recorded the following parameters: engine load, coolant temperature, intake air pressure, crankshaft speed, vehicle speed, air temperature, air mass flow, pressure in the fuel rail, battery voltage.

A one-week driving tests were performed in urban and non-urban traffic and the data was recorded with a $5 \mathrm{~Hz}$ frequency. Ambient conditions were similar during each of the driving tests, and each of the drives was not less than 10 min. The tests were carried out in Lublin city and in Lublin province. Mean vehicle speed was $21 \mathrm{~km} / \mathrm{h}$ in urban cycle and $52 \mathrm{~km} / \mathrm{h}$ while driving non-urban cycle.

The NI Diadem software created the distribution of engine operating density at a specific engine speed and load. Our calculation was in line with a special script.

The results are given as histograms and contour plots. The load ranged from 0 to $100 \%$, whereas the speed from 700 to 3,200 rpm. During analysis the measurement ranges were divided for load is $5 \%$, whereas for crankshaft speed is $100 \mathrm{rpm}$.

\section{Result examination}

The first part shows the registered engine load and crankshaft speed as a function of driving time for the selected non-urban driving test.

The second part shows the contour plots of the frequency of engine load and the histograms of the engine load and the crankshaft rotational speed for the selected urban and non-urban driving tests. Because of many testing drives, this paper shows the data for one driving test under given traffic conditions only.

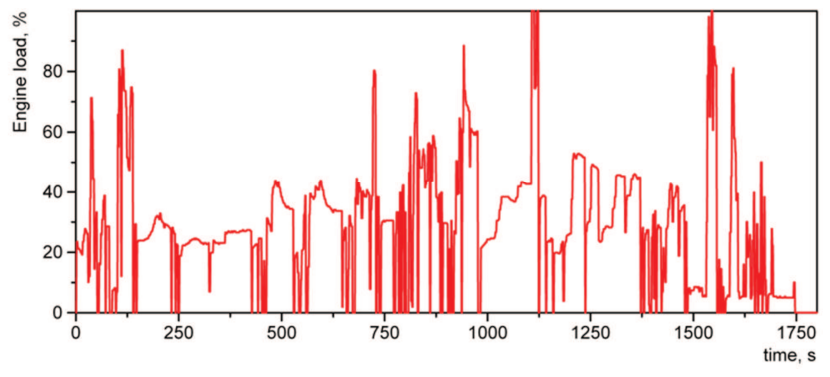

Fig. 4. Load as a function of driving time 


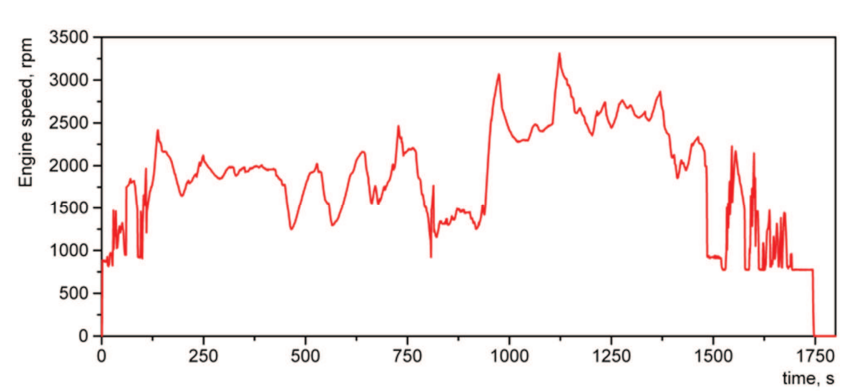

Fig. 5. Crankshaft speed as a function of driving time

The engine was at idle at first (about $750 \mathrm{rpm}$ ) and then the crankshaft speed increased as the vehicle accelerated to about 2,500 rpm (Fig. 4). Speed in the further part of the drive was not relatively constant as in the first period of time, i.e. $250-750 \mathrm{~s}$ it ranged from 1,400 to $1,700 \mathrm{rpm}$ and later, i.e. 1,000-1,300 s increased and ranged between 2,300 and 2,600 rpm (Fig. 5).

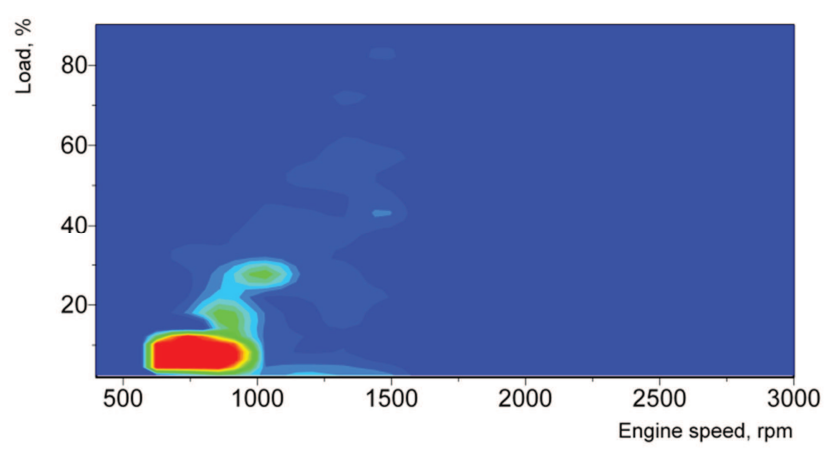

Fig. 6. Engine load frequency as a function of engine speed and load for urban traffic

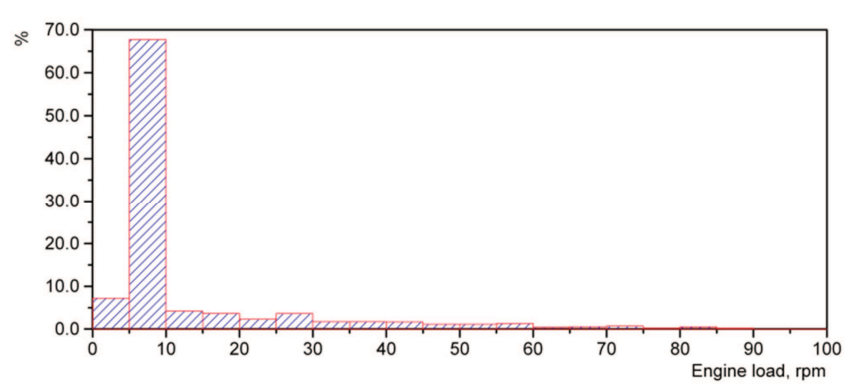

Fig. 7. Histogram of the engine load for urban traffic

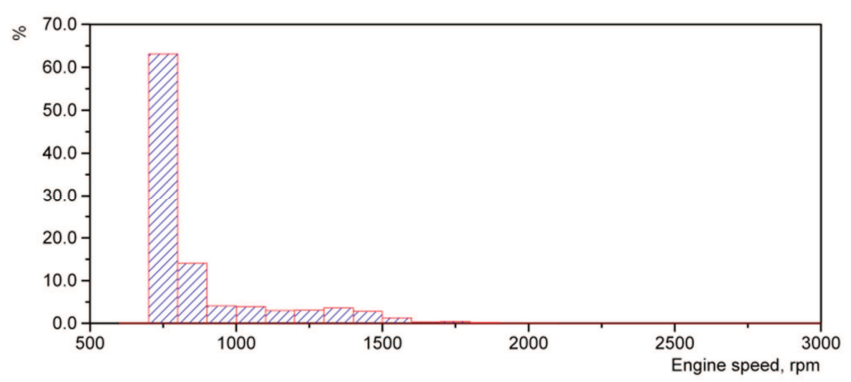

Fig. 8. Histogram for crankshaft speed for urban traffic

The load frequency as a function of speed and load is in Fig. 6 and the histograms of the frequency of engine load and speed for the selected urban test drive are in Figures 7 and 8 , respectively.

The most frequent load of $0-10 \%$ corresponds to the idling speed of 700-900 rpm, which results from the fact that the vehicle often stopped during the urban drives because of heavier traffic, signal lights and other traffic disruptions. The most frequent load range for the research engine was $5-10 \%$ and the frequency of this range was about $68 \%$. The urban engine load reached $80 \%$, but the lowest frequency was in the load range of $75-80 \%$. Idling speed, i.e. about $750 \mathrm{rpm}$, was most frequent, and the least frequent speed range was 1,875-2,000 rpm. The frequency of idling speed was about $63 \%$. The urban engine speed range was 700-2,000 rpm.

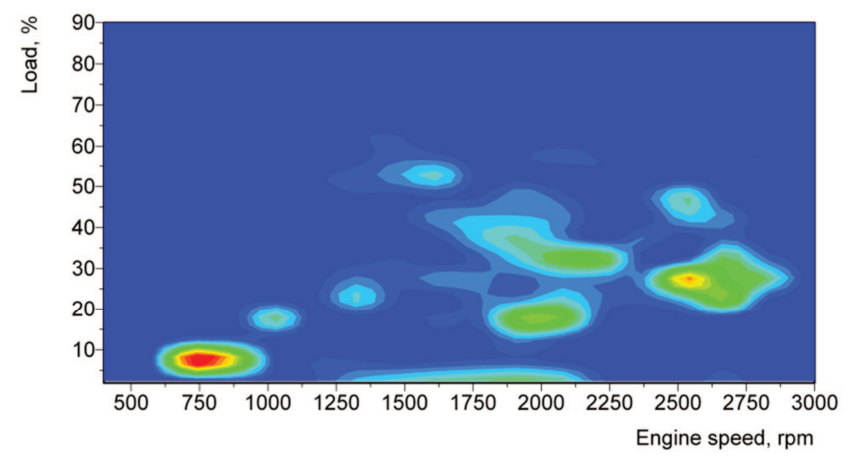

Fig. 9. Engine load frequency as a function of engine speed and load for non-urban traffic

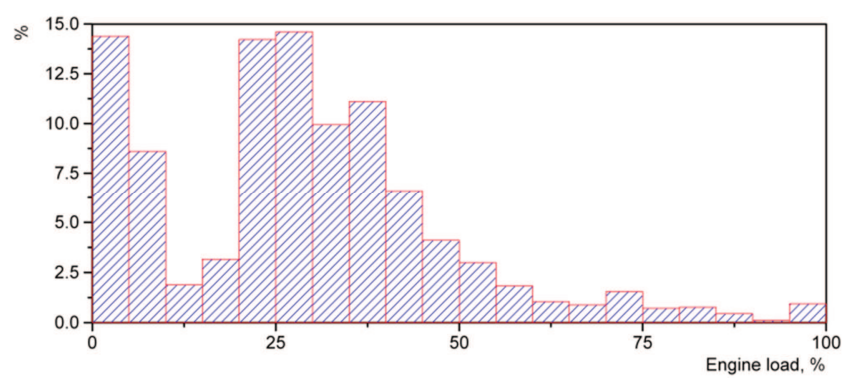

Fig. 10. Histogram for engine load in non-urban traffic

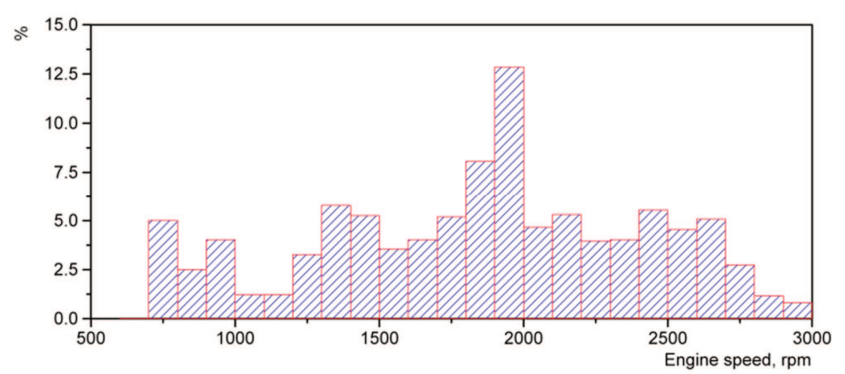

Fig. 11. Histogram for crankshaft speed in non-urban traffic

The load frequency as a function of speed and load is in Fig. 9 and the histograms of the frequency of engine load and speed for the selected non-urban test drive are in Figs 10 and 11 , respectively.

The most frequent load ranges are: $0-10 \%$ - this range corresponds to the idling speed of 700-900 rpm and 20-30\% - this range corresponds to the speed of 2,450-2,600 rpm. The former frequency results from the fact that the vehicle 
often stopped in the non-urban drives because of traffic and other traffic disruptions. The latter one reflects constantspeed driving. The frequency of the $5-10 \%$ load range reached about $22 \%$, whereas that of $20-30 \%$ was about $29 \%$. The non-urban traffic engine load was nearly $100 \%$, but the load range of $90-95 \%$ was least frequent. The most frequent speed was $1,875-2,000 \mathrm{rpm}$, and the frequency of this range was about $12,5 \%$. The non-urban traffic crankshaft speed was within the range of 700-3,000 rpm.

\section{Conclusions}

The research aimed at specifying loads of the passenger car CI engine that operated in urban and non-urban traffic.
It should be also noticed that obtained results concern one type of engine.

Installed in the Mazda 6 passenger car, the OBD Log device measured engine load.

Regarding the results, it can be claimed that the engine is loaded less in urban than non-urban traffic because of road conditions in the city like heavy traffic, signal lights and road works.

It can be concluded that the engine operates in urban traffic mainly at idle and a negligible load of about 5-10\%, whereas in non-urban traffic it more often operates at higher speeds, i.e. 1,800-2,100 rpm and the larger load of 20$35 \%$.

\section{Nomenclature}

DPF diesel particulate filter

EGR exhaust gas recirculation

EOBD European On-Board Diagnostics

HCCI homogeneous charge compression ignition

OBD on-board diagnostics

PEMS portable emission measurement system
RCCI reactivity controlled compression ignition

RDE real driving emission

TTW tank-to-wheel

VGT variable-geometry turbocharger

VMT vehicle miles traveled

\section{Bibliography}

[1] Provisional Road Traffic Estimates, Department for Transport, Great Britain: January 2016-December 2016 Summary.

[2] QUIANFAN, X. Diesel engine system design. Woodhead Publishing Limited, 2011, 115.

[3] HEYWOOD, J.B. Internal combustion engine fundamentals. McGraw-Hill Education. 1988, 839.

[4] WANG, Y., YAO, M., LI, T. et al. A parametric study for enabling reactivity controlled compression ignition (RCCI) operation in diesel engines at various engine loads. Applied Energy. 2016, 175, 389-402.

[5] BLANCO-RODRIGUEZ, D. Modelling and observation of exhaust gas concentrations for diesel engine control. Springer. 2014, 62-63.

[6] ANDRÉ, M. The ARTEMIS European driving cycles for measuring car pollutant emissions. Science of The Total Environment. 2004, 334-335, 73-84.

[7] POSTRZEDNIK, S., STOPA, P., CIESIOŁKIEWICZ, A. The analysis of loading state of combustion engine in different variants of its work. 26 Międzynarodowa Konferencja Naukowa Silników Spalinowych. Nałęczów, 2000, 235-244.

[8] RAKOPOULOS, C.D., GIAKOUNIS, E.G. Diesel engine transient operation - principles of operation and simulation analysis. Springer. 2009, 4.

Łukasz Grabowski, DEng. - Faculty of Mechanical Engineering at the Lublin University of Technology.

e-mail: L.Grabowski@pollub.pl
[9] YUM, K.K., LEFEBVRE, N., PEDERSEN, E. An experimental investigation of the effects of cyclic transient loads on a turbocharged diesel engine. Applied Energy. 2017, 185, 472-481.

[10] BARDEN, J., GEROVA, K. An on-road investigation into the conditions experienced by a heavy goods vehicle operating within the United Kingdom. Transportation Research Part D. 2016, 48, 284-297.

[11] GALLUS, J., KIRCHNER, U., VOGT, R., BENTER, T. Impact of driving style and road grade on gaseous exhaust emissions of passenger vehicles measured by a Portable Emission Measurement System (PEMS). Transportation Research Part D. 2017, 52, 215-226.

[12] KWON, S., PARK, Y., PARK, J. et al. Characteristics of on-road NOx emissions from Euro 6 light-duty diesel vehicles using a portable emissions measurement system. Science of the Total Environment, 2017, 576, 70-77.

[13] TRAVESSET-BARO, O., ROSAS-CASALS, M., JOVER, E. Transport energy consumption in mountainous roads. A comparative case study for internal combustion engines and electric vehicles in Andorra. Transportation Research Part D. $2015,34,16-26$.

[14] motofocus.pl/informacje/nowosci/6135/bez-zadnychtajemnic-obd-log-texa

Paweł Karpiński, MEng. - Faculty of Mechanical Engineering at the Lublin University of Technology.

e-mail: Pawel.Karpinski@pollub.edu.pl
Damian Rudzik, MEng. - Faculty of Mechanical

Engineering at the Lublin University of Technology.

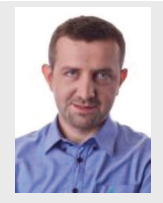

